system consists of horizontal dipoles connected to the terminal apparatus by special transmission lines, and the whole equipment has been designed to work unattended, apart from periodic maintenance operations.

\section{British Standard Specifications}

The British Standards Institution has for its principal object the co-ordination of the efforts of producers and users for the improvement, standardisation, and simplification of engineering and industrial materials. It specifies standards both of quality and of dimensions in order to assist production and distribution and to eliminate waste of time and material involved in the unnecessary variation of articles made for the same purpose. Thereby it contributes to safety as well as to efficiency in industry, as is evidenced by the recent publication of a British standard specification for the identification of chemical pipe lines. The proposed scheme, which was prepared at the joint request of the British Chemical Manufacturers' Association and the British Chemical Plant Manufacturers' Association, identifies the nature of the liquids or gases conveyed by means of coloured plates, bearing a distinctive letter or sign, which are to be placed adjacent to the control valve and at intervals along the pipe. Thus a workman can immediately ascertain whether a certain pipe conveys inflammable, explosive, toxic, or corrosive material, whether the contents aro under pressure, or whether the pipe line is safe. The matter might at first sight appear to be a trivial one which could be left to the common sense of works managers; in practice, however, the proposed universal device will help to avoid the possibility of emergencies ending in tragedies.

\section{Research on Coal and Coke}

THE third annual report of the Northern Coke Research Committee records the many-sided activities of its staff working in the Armstrong College, Newcastle, on problems of the coals and cokes of the north of Fingland. Like most organisations, the Committee now labours under restrictions imposod by the financial stringencies of the times. Apart from fundamental long-range investigations, there is an immediate need for documented information about the characteristics of commercial fuels, which is felt by anyone concerned with the rational choice and utilisation of available coals. To-day coal is no longer the unchallenged king of fuols. The tendency with all commodities is to look for products regular in supply, of high and uniform quality. In all these respects coal has displayed an inferiority against its competitors, and it is hard to see how the industry can maintain its position against its cornpetitors by abandoning or diminishing efforts to inform itself about the properties of its wares. The Report for 1930-31 of the Department of Mining and Fuel Technology of the University of Shefficld also records a wide range of investigations connected with the winning and utilisation of coal, many of which have already been noticed in our pages.

\section{Modern Tendencies in Bird Taxonomy}

The appearance of a fourth edition of the American Check List of Birds in 1931 has suggested to Joseph Grinnell a comparison between its contents and that of previous editions (Auk, Jan. 1932, p. 9). The result is a vivid picturo of the tendency of modern taxonomic studies. The first edition appeared in 1886 , and subsequent editions in 1895,1910 , and now the fourth in 1931. The total number of forms, species, and sub-species listed in these editions was 951, 1068, 1196 , and 1420, a very considerable increase in about a working life-time. But a further examination shows that the increase is not equally distributed: the numbers of full species were 768,799, 802 and 811 , a remarkable stability of numbers during the period, less than one new species a year being described. On the other hand, the number of sub-spocies has mounted very greatly-183, 269, 394 and 609 -and the tendency to multiply sub-species is shown most strongly in the last edition. There has been a great advance in the identification of fossil species, the numbers of which run, $46,64,72$, and 156 , but this is a very natural development, for recent years have seen intensive fossil collecting in many areas. The author's idea is that the tendency marked in the new edition is bound to grow, that interest in phylogeny and species-making are counterparts, and that the "species factory in nature is the only resort in final analysis for learning the true nature of the speciation process. More and more alert, students in the field of systematics will develop a facility and technique of discrimination scarcely to bo dreamed of now." On the other hand, it is possible that the future will bring, rather than a development of description for its own sake, an association between specific or subspecific forms and their environment so close that systematic description apart from referenco to pecu. liarities of life-conditions will be regarded as inadequate.

\section{Progress at Colombo Museum}

THE building of a new west wing, a new isolated archæological gallery for stone remains, and a small building for the entomologists' department and reserve collections, has provided nearly 13,000 square feet of additional space for the public collections of the Colombo Muscum. The exterior of the west wing conforms with the style of the older portion of the museum, and the block, which, as a photograph shows, is a very handsome structure, stands out as one of the finest buildings in Colombo. It is illustrative of the difficulties of museum lighting that although at most seasons the light is too intense for spocimens and sight-seeing, during cloudy days in the monsoon period the lighting in the old building was found to be inadequate, and accordingly special provision has been made for artificial lighting from the roof and within the cases (Administration Report of the Director of the Colombo Museum for 1931). Many additions have been made to the Museum collections, but the section which still retains greatest hold upon the visitor is the collection of living animals, which contains a good selection of mammals 